\section{M\&M 2002: Core Facility Management Session Maintaining Major Equipment in the Core Microscopy Facility}

Session Chair: Debby Sherman, Purdue University dsherman@purdue.edu

Part I: Servicing by Original Equipment manufacturers: the structure, function \& considerations for assembling \& operating a major service organization

D. Sherman: This session centers on approaches to maintaining major equipment-primarily electron microscopes. I thought we ought to look at how effective it is to service with onsite engineers. So with that I would like to start us out with Pat McGinley from JEOL.

$P a t$ is a long-time JEOL employee. He started out as a service engineer in 1976 and is currently Vice President of Service and a member of the Board of Directors for JEOL USA.

Pat McGinley (JEOL - mcginley@jeol.com):

\section{JEOL SERVICE: CHOICES / Service Organization:}

What I wanted to start with are the choices you have to make when you are putting together a service organization. The first choices you need to make is: should you be a centralized dispatch system or distributed system? I won't speak in detall about a centralized dispatch system today but did want to mention it. This is where you call into a centralized number, are given a ticket number, and someone eventually gets back to you to schedule service. A distributed system is a little more complicated, costly and complex. You also have to be more careful about schedule synchronization. We have the United States broken down into the East, Central and West regions. Each of these regions is broken down into districts with each district having no more than 250 customers and no more than 22 service engineers. JEOL is represented in Canada with an office in Montreal and 10 service engineers stationed across Canada who support approximately 125 customers. Mexico has an office staffed by management and approximately 5 service engineers. We feel that this provides us with more personalized service. The managers in these offices get to know the customers quite well, the engineers get to know the customers quite well, and vice versa. In addition, it is necessary to have all of the schedules synchronized with the national headquarters so someone knows exactly what is happening across the country and the continent at any one time.

Another way to look at our service organization would be with an organizational chart. The national office is in Peabody, MA. In this location we have more than 15 factory-trained specialists from Japan who come to the United States for a 3-year period. They rotate back to the factory so that we keep the latest technology knowledge in the States. These specialists are here to support our field engineers as well as to support on-site customer service.

A few of the other major issues/choices for a service organization are:

- Staffing levels: the number of installations and the number of contract

customers that we have determines staffing levels.

- Customer locations: we try to match up our engineer locations with those customers.

If we were to draw a 100 -mile radius around each of our engineer's locatons we can cover greater than $93 \%$ of our customers without having to fly. This keeps our field service staff happy, as they are not very interested in traveling and spending time away from their families, which in turn raises our employee retention rate. It also gives us a better response time for our customers.

Another issue we need to address would be the salary issue. Salary is very competitive today. Service engineers for electron microscopes must have an enlarged set of skills. They must have knowledge of electronics, mechanical systems, vacuum, as well as a strong understanding of computers and networks. These employees have become very valuable not only to JEOL and other electron microscope companies but to almost all other companies out there. It was very difficult to try and keep our employees at JEOL when the semi-conductor industry was booming. Also just this year alone we have had two Universities hire away 33 years of experience from JEOL. So when it comes to trying to keep employees, we have many of our customers being somewhat of a competitor.

The benefit packages that must be provided in order to retain field staff is currently running about $26 \%$ of the total compensation for the year. We do over 4000 hours of training per year on an internal training basis. That amounts to a cost of around $\$ 800,000$ for internal training if we assume a modest rate of $\$ 150 / \mathrm{hr}$. Outside training is well over $\$ 200,000 / y e a r$. Therefore JEOL spends approximately 1 million dollars/year on service engineer training.

We are required to carry a number of different types of insurance coverage. In 2001 there was a substantial increase in insurance cost, $17 \%$ over the previous year, while the 2002 increase is even higher at $20 \%$. I know that our service contract prices have been increasing, but they do not increase at anything near these rates. The contract increases have been in the 3-4\% range.

Inventory level is another major concern for anyone trying to establish a service organization. If you are the manufacturer of the product you have to carry inventory. We have over 12 million dollars of inventory located in three different sites across the country, strategically placed in Massachusetts, Texas, and California. We also carry over 12,000 unique items. These are items that you can't go out to an electronics shop or vacuum component supplier and purchase because they are unique to our instruments. We have to carry them locally so they can be available to our customers for emergency over-night delivery. In addition to the stock we have in the States, Japan carries stock at the International Parts Center and has approximately 23 million dollars invested in parts stock at this time.

\section{SERVICE CONTRACTS:}

Twelve years ago the service contract offerings would have been full service only. You had one choice and could either buy it or settle with demand service (per diem). Today we are working with our customers to provide everything from a limited service contract to a $24 / 7$ contract. The limited service contract limits the number of days you have and the amount of parts that are supported, while $24 / 7$ provides complete coverage any time or day of the week. If uptime is a requirement, you are further up the scale. If uptime is not as critical than we can move the scale down a bit and balance risk between us.

The JEOL service commitment includes the following:

- Continuous support guarantes: If you buy service contacts from JEOL, we will continue to renew your contracts year after year. We had one customer who had an instrument on service contract for 27 years. We convinced another customer after 21 years of operation that they should start to think about trading up. After 23 years they did buy an updated instrument that was much younger than the one we were supporting, so we were very appreciative of their decision.

- Instrument performance quarantee: If you have a service contract with JEOL you can, at any time, ask us to come in and reproduce the factory specifications the instrument had when initially installed. The contract insures that the instrument does not loose performance and maintains value in your facility.

- Quality repair guarantee: Purchase of a full service contract gives an automatic $90 \%$ up-time guarantee. We automatically credit the next year service contract or refund that amount of money if any of our customers who have purchased a full service contract have down time that exceeds $10 \%$. If you buy the $24 / 7$ contract, you get up to $96 \%$ up-time guarantee.

\section{Sherman:}

Our second speaker is Mike Kearney. Mike Kearney is Director of Service for $\mathrm{FEI}$ and is currently responsible for the Electron Optics Products service portfolio in North America.

\section{Mike Kearney (FEI - mkearney@feico.com):}

FEl's intention is to provide tier one service support. We are committed to our customers and to having highly trained service engineers and properly stocked inventory to meet your service needs. It is necessary for us, as a service organization, to operate as a profit center to maximize these efficiencies by financial accountability. This method stabilizes service, making it impervious to the revenue fluctuations of instrument sales cycles. We all know that we have gone through about the worst two years in the history of this industry. FEl is a world-wide service organization. We have technical assistance centers located in all time zones. We have factory support from technical engineers from the factory for each product line. We have one call center in the United States that provides single point contact. When you call in you should have an engineer cal you back within 60 minutes. Someone will then be on site depending on which contract option you have chosen. We also have spare parts inventory located in 5 or 6 strategically placed regional depots throughout the United States.

I was asked to show some of the contract options we have. We typically offer three lab contracts:

- Basic: labor and travel only with parts not included

- Standard: full coverage including labor travel and parts-that is 5 days week and $8 \mathrm{hr} / \mathrm{day}$.

- Premium: full coverage and $24 \mathrm{hr}$. response

We also offer extended contracts that we call production contracts and engineer-on-site contracts for people having 7 days per week and $24 \mathrm{hr}$. per day needs. Obviously having service contracts permits accurate budgeting of servicing expenditures by providing fixed costs for the coverage period, It limits the cost of in-house personnel, diagnostic tools, and parts inventory. It also decreases downtime by promptly providing factory trained service engineers and avoids the customer waiting for service while purchase orders are approved. It seems to be a bigger and bigger issue to get a PO if parts are required. Regular service extends the life of the product. It provides peace of mind and reduced anxiety by assuring that your instrument failures will be repaired with no additional cost. Service contracts also offer preferred response times and 


\section{EDX \& Imaging Systems}
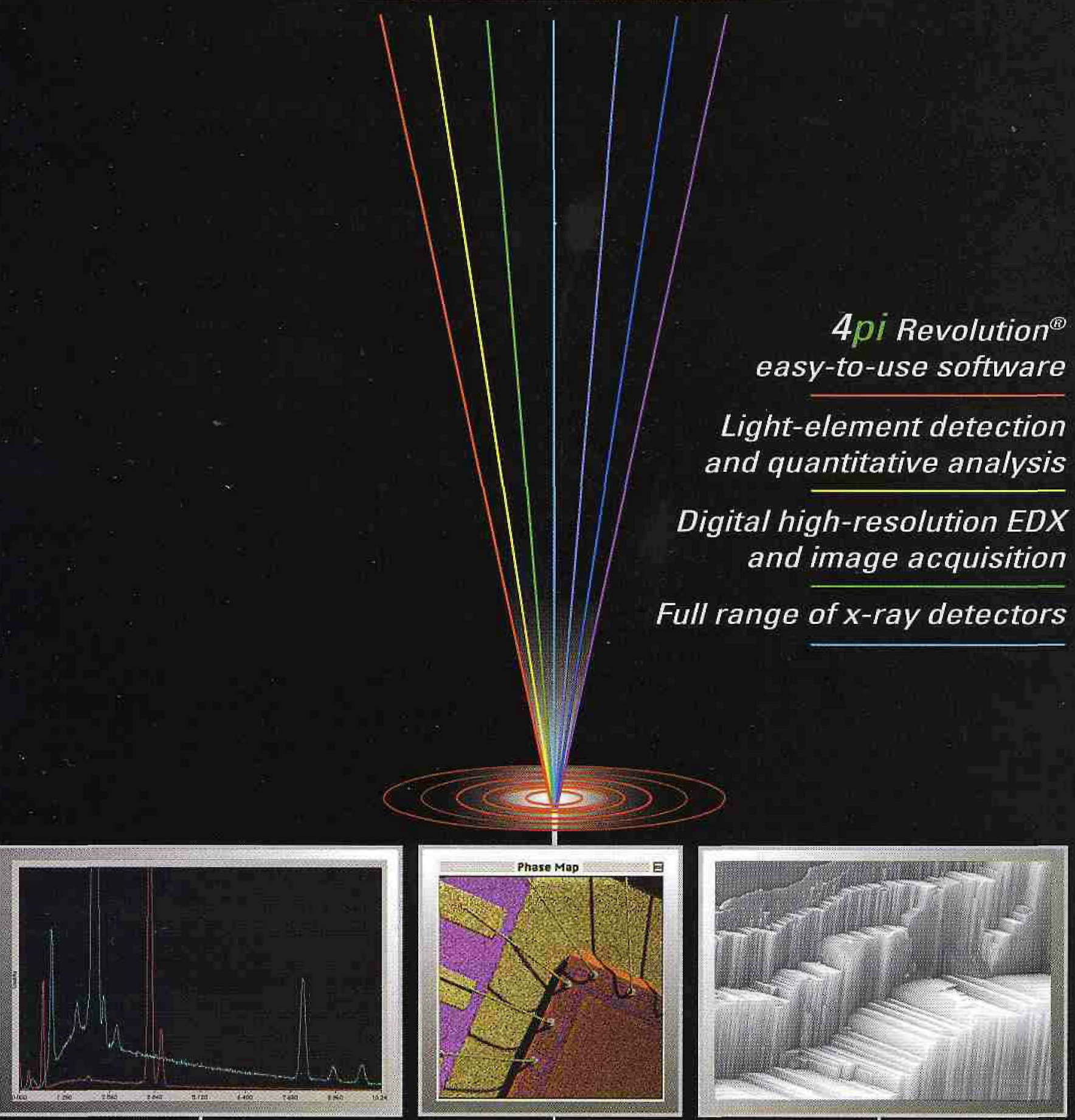
prierity parts availability over non-contract customers.

I anticipated that this would go into a question and answer format so have made my initial comments short. Thank you very much.

D. Sherman: Our next speaker is Greg Rigby. Greg is Senior Director of Service Operations for Hitachi High Technologies America, Inc.

Greg Rigby (Hitach - rigby@hii-hitachi.com):

Many of you may not know that Hitachi recently merged a few of our divislons in the United States and in Japan. We were operating as Hitachi Instruments in the USA, providing service support and light manufacturing. Another company, Nissei Sangyo America, provided the sales and marketing for all Hitachi EM products. These companies joined together to form a new corporation called Hitachi High Technologies America. We realize that cost is a major concern; it is a concern to every business and entity out there today. I will explain what we see as our driving factors that cause us, as an OEM supplier, to be more expensive than third party and self-maintenance organizations.

Mission Statement:

In regards to our mission statement, we strive to become the premier supplier of leading-edge high-quality equipment and services to the scientific and business communities. We reveal the nano-world to enable the development of innovative technologies to preserve the environment and improve the global quality of life.

Customer Expectations:

What do customers expect from OEM suppliers? The equipment should have a high reliability and superior technical performance. Many of today's microscopes are achieving resolutions that were unheard of a few years ago, with superior reliability. Companies today must be able to demonstrate an effective return on investment or lower cost of ownership.

- Technical support: Customers today expect to have knowledgeable customer support representatives when you call into the call centers that we have established. You expect that they will be able to locate you in our data base, log the service calls, take parts orders and be able to assist you on a $24 h / 7$ day a week call basis. We are expanding into manufacturing environments that have operations running $24 / 7$ and we must establish an infrastructure to meet these needs. This operation dramatically increases our operating expenses.

You like to speak directly to our technical support staff during your initial call when you are experiencing problems with a system. You don't want to wait two or three hours for someone to call you back. You are working on the problem now. Two or three hours from now you are going to be working on something else if you were unable to solve that problem. So again, we must have technical staff available even though this is a difficult thing to do as it drives up operating costs. We try to monitor our staff throughout the field and utilize our field personnel for this task as they are not utlized 100 percent of the time. With phone switches and the technology of today we can often route you directly to a particular individual as though he is sitting inside our office. A complex problem can often be solved with the use of technology and helps reduce operating expenses.

- Parts: We need to have the parts available and hopefully at the site when the engineer arrives. In some cases, we identify the part after the fact and it has to be shipped in. The parts must be reliable and low cost. From time to time we utilize "counter to counter" shipping authorization as we have agreements with United and American Airlines to ship emergency parts in the event an overnight delivery is unacceptable.

- Management: Management must have a technical understanding to support the field. We should be able to manage our inventory, manage our staff, and try to control our costs so that we can pass those savings on to the users.

Some of the challenges we have as an OEM supplier:

Our goal is to maintain, motivate, and create long-term career opportunities for personnel. So what makes or breaks a great support organization? "Longevity". We cannot have uncontrolled turnover and try to control turnover at all costs. If we know someone is going to leave, we can begin to plan how we are going to handle replacements. But when somebody abruptly leaves the organization, it creates a huge vold that increases our costs. Some of the impacts to our companies by loss of expertise are:

- We lose customer confidence and increase expenses by increasing travel, training, etc. If you have had a service engineer for years and he suddenly leaves, customers' lose respect and confidence in the company and fear that we will no longer be able to properly support their system.

- The loss of support employees' places increased pressure on the trainers and co-worker's as backfill is required from other locations.

- The sales team gets upset if the customer base is not happy in an area and they begin saying, "We are not going to buy another Hitachi microscope as we question your ability to support it."

There are a few positives that come out of this. New graduates gener-

\section{Scalpels to Scoops to Screwdrivers to Spatulas to Speedles to Sputter Coaters}

Carbon Coaters to Clip Mounts to Carbon Rods to Custom Equipment Beakers to Beam Stops to Boats to Books to Bottles to Boxes Tape to Timers to Titanium Tweezers to Tensile Testers Pipettes to Planchets to Pithwood to Power Supplies Hacksaws to Hex Grids to. Heating Stages Universal Holders to Uranyl Ace Vacuum Pumps to Viewing Boxes Wafer Tweezers to Work Holders Magnifiers to Micromanipulators Desiccators to Dropping Bottle: Latex Spheres to Lens Tissue EFFA Dusters to Evaporators Glass Bottles to Orid Boxes Razor Blades to Ruby Mices Ferritin to Films to Forceps Acetone to Apertures

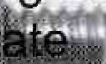

What can you imagine?
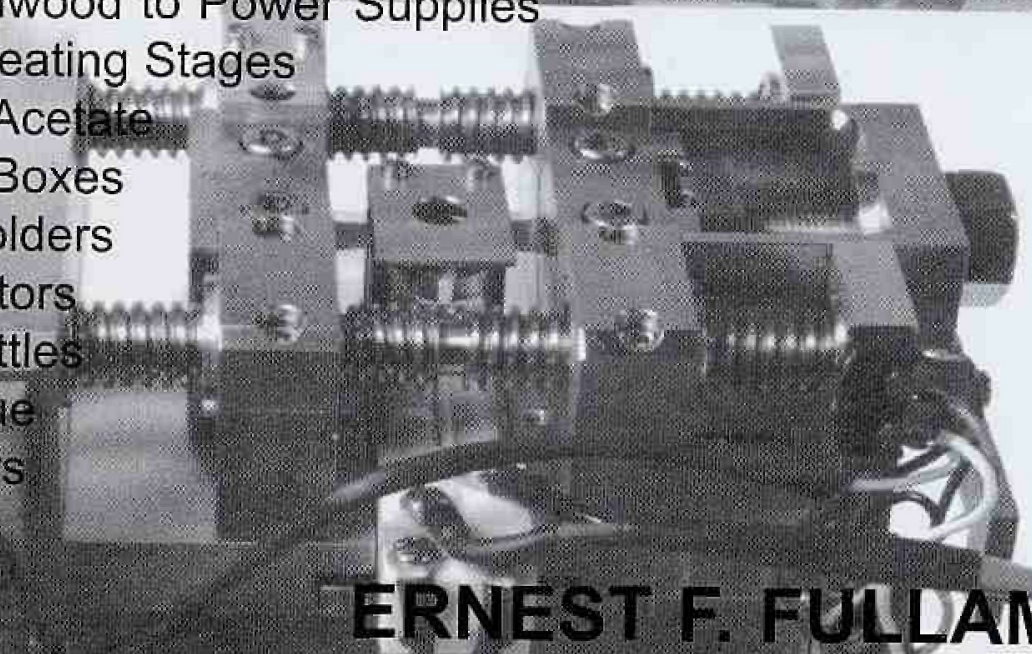
ERNEST F. FULDAM, INC.

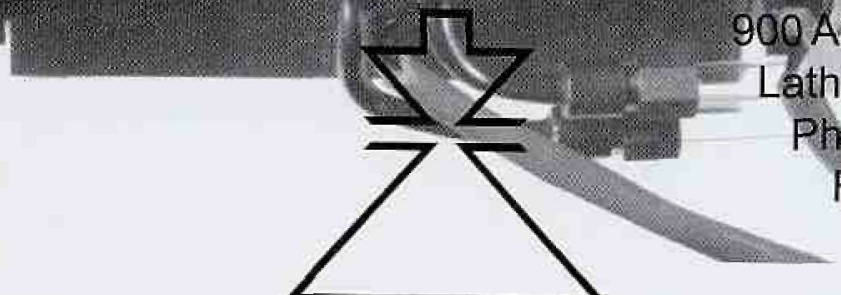

00 Albany Shaker Road atham NY 12110-1491 Phone: 518 785-5533 FAX: $518785-8647$ sales@fullam.com www.fullam.com 


\section{Carbon Build-up?}

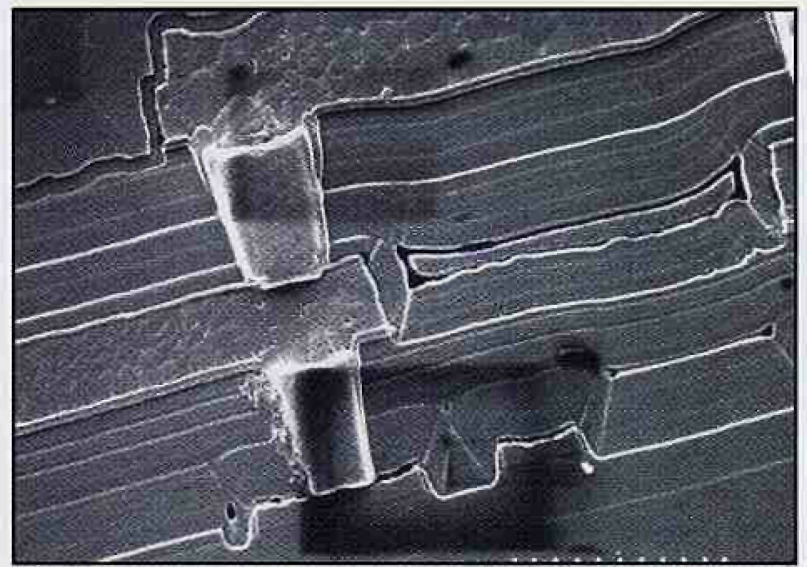

Scan marks and e-beam induced, organic deposits can hide features during SEM imaging.

\section{The Evactron ${ }^{\circledR}$ RF Plasma Anti-Contaminator cleans it up}

NEW：Evactron $\left({ }^{\circledR}\right)$ Model 10

Designed for easy cleaning of any SEM or FIB with little operator adjustment. Select a cleaning time (2-5 minutes typical) and partially vent chamber and restart evacuation in roughing mode. When the pressure reaches $0.6 \mathrm{Torr}$, the Evactron A-C opens an air leak into plasma chamber and a RF plasma makes Oxygen radicals to flow into main chamber to ash organics away. Pressure and RF power are automatically adjusted to optimum cleaning condition at factory preset levels.

- Removes organics from any source! Specimen born, pump oils, GIS gases, instrument sources, and vacuum accidents.

- Gentle cleaning action is proven safe for EDS and other sensitive windows.

Evactron ${ }^{B}$ Models B \& C

Improving on the original Evactron Sem-Clean ${ }^{\mathrm{TM}} \mathrm{A}-\mathrm{C}$ these models have manual pressure and RF control to provide Evactron cleaning at a budget price. Model $\mathrm{C}$ is $\mathrm{CE}$ marked for Europe.

M\&M 2003 Booth 707

\section{XEI SCIENTIFIC}

3124 Wessex Way, Redwood City, CA 94061 (650) 369-0133, FAX (650) 363-1659 email:sales@Evactron.com wWw.EVACTRON.COM

\section{Mieroseopy Auctions}

- Over 200 Microscope ads online daily

- Buy \& Sell all major brands

- Free "Wanted" ads for quick results

New - Eur plus - USEe] Microscopes, Accessories, Objectives
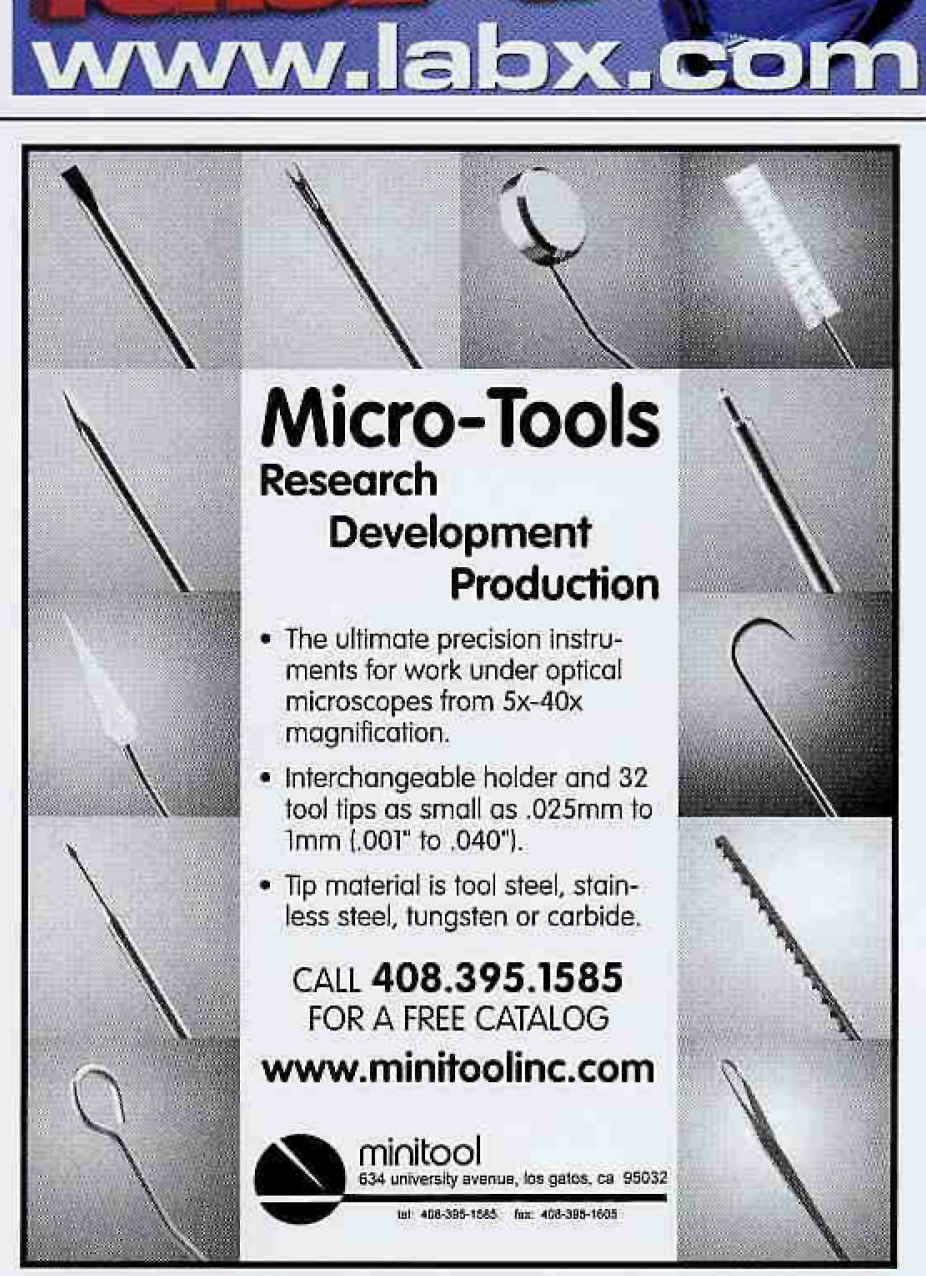
ally have a greater understanding of computer and other newer technologies, enabling them to come in and quickly connect networks and other system configurations. As to staffing goals, we're broken down into districts. We map where we have instruments around the country and position engineers and offices to establish an effective organization. We try to maintain an acceptable man-to-machine ratio. In 1999 we were running about 19 tools in the field per service engineer. 2000 was about the same, in 2001 it jumped up to about 21 as the economy continued to expand. We started to loose our responsiveness to the install base so we hired and trained additional support personnel to bring the level back to 17 in 2002. These support levels are difficult to maintain as the economy continues to decline.

We have millions of dollars invested in spare parts inventory. This inventory is a high cost and is constantly being reviewed by the company. About $38 \%$ of the parts are considered slow moving or inactive. There are circuit boards and other parts that were put in stock in 1985, on anticipation that some day they would be needed, that have never left the shelf. We are currently supporting 75 different models. $6.6 \%$ of the inventory is used to support 28 models that we now consider obsolete. Replacement parts for computers are one of the biggest challenges we face today as this technology becomes obsolete after a year or two. A workstation or PC basically drives every new microscope sold today. In many of these computers we have specialty boards located inside that work with specific chip sets and these change almost yearly. When we learn of a computer end-of-life announcement, we make a one-time purchase in order to stabilize a supply to lower the cost of future repairs. Otherwise, we must upgrade the system. These upgrades can require extensive changes, such as operating systems and other unique hardware changes to get the instrument compatible to the next generation of computer.

We are beginning to look at inventory issues on a global basis are trying to eliminate duplication of some parts that have been sitting on our shelves for $10-15$ years. We have parts stocked around the world and can look at inventory globally and find out if Singapore, London, or one of our other affiliated operations has one of these parts in stock. We need them sitting in one location somewhere in the world where we know, if we need it, we can get it within a reasonable period of time.

Newer Technology is requiring more advanced training, much of which is achieved by providing dedicated training classes. Designed specifically to: pinpoint hardware \& software; how to trouble shoot the machine; diagnostic routines that can be used; tuning the machine; obtaining resolution; performance

\section{Software to Make Your Job Easier, and a Free X-Checker Too!}

For a limited time, get a free $X$-Checker calibration/performance standard (a \$250 value) when you purchase Electron Flight Simulator.

\section{Electron Flight Simulator} became the world's leading $\mathrm{SEM} / \mathrm{X}$-ray visualization software by showing you how your sample behaves under all conditions
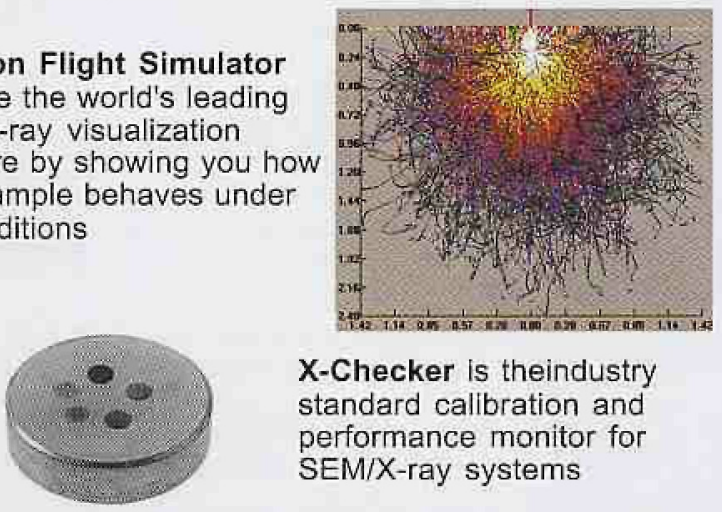

$\mathrm{X}$-Checker is theindustry standard calibration and performance monitor for SEM/X-ray systems

Put both to work in your lab and save $\$ 250$ !

www.small-world.net (703) 849-1492
Gapability of the stage, etc, It requires a significant amount of time to train people on how to get the proper gear mesh or torque on the stage drives. We have dedicated trainers and a new training facility that we just opened in Pleasanton California where we are conducting all of our customer maintenance courses and field service operation classes.

From time to time, intermittent, or difficult to isolate problems, require replacement of expensive PCB's or other components to assist in isolating or identifying the root cause. This is evident, as many times our inventory will leave our building only to be returned because it is being used for diagnostic purposes. You need to have parts available to figure out what is going on in order to be able to solve some of these intermittent problems. While our systems today have advanced diagnostics capabilities, we are constantly pushing our designers to build in better diagnostics on these boards. That way we won't have to keep large inventory levels in order to be able to troubleshoot tools. As time goes on, we do expect to see continuous improvements in this area. Third party and self- maintenance facilities have cost advantages due to lower cost of operations. They don't have millions of dollars invested in inventory. They don't have $100+$ service engineers stationed throughout the country and a machine ratio of 17 or 20 . These are things that we must do as an OEM to sustain our business and the customers' confidence even though it is a significant cost to us.

We are not in the business of making money off of the services provided. If we could design these tools so we could do away with the entire support operation it would be done. Providing service is something we have to do in order to sustain our future business. One thing we can do to lower the cost to the end user is to take advantage of e-diagnostics - this is a solution available today. However, there are still security issues that we need to deal with. We need to give the confidence to the users that no one is going to hack into your system and steal your information or corrupt your microscope. Perhaps we can introduce this technology to some of the other microscope users in the field,

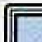 \\ Position Available Brigham Young University Technical Administrative Staff}

The College of Physical \& Mathematical Sciences at Brigham Young University (BYU) invites applications for a technical administrative staff position in support of the transmission electron microscopy laboratory. The position will be administered in the Department of Physics \& Astronomy. The laboratory is located in a new state-of-the-art facility that will house both a $200 \mathrm{KV}$ ultra-high-resolution (S)TEM and a $300 \mathrm{KV}$ TEM, with multiple specimen preparation support labs. Analytical capabilities include EDS and EELS. An M.S. degree, or comparable experience, (Ph.D. degree preferred) in physics, materials science, or a related field is required, plus at least 2 years experience in operating and maintaining transmission electron microscopes for materials applications. The successful candidate must have the ability to train users in both sample preparation and TEM use, to interact effectively and collaborate with users from advanced undergraduates through faculty from a variety of disciplines, and to maintain the instruments and interact with manufacturers service engineers, as appropriate. BYU is sponsored by The Church of Jesus Christ of Latter-day Saints (LDS, Mormon) and is an equal employment opportunity/affirmative action employer. Strong preference is given to LDS applicants. Employees are required to abide by standards consistent with LDS values. Contact E. Daniel Johnson, N-181 ESC, BYU, Provo, UT 84602. Applications will be accepted until a successful candidate is identified. This is a permanent, full-time, budgeted position. 
such as universities or small business where monies for service contracts is limited. If we can do it on a smaller scale, than maybe we have an opportunity to lower some of our operating expenses and be in a position to pass on the savings to our customers. We are confident this can help reduce the time it takes to repair the equipment, reduce the inventory by being able to remotely diagnose problems, obtain the correct parts on site prior to the FSE arrival and maybe eventually be able to lower our head count.

OEM service operations are business units and should be self-sufficient to sustain their business operation. To a certain extent, the sales do support the organization but what is the responsibility of an OEM supplier for a 20-year-old machine? Should the support cost for machine be subsidized by the company? The company would not be able to maintain its business operation if we were to support those machines at our cost for 20 years. As new equipment is sold, we receive money from the sales organization toward installation expenses. The Service department has a large staff that requires us to encourage and motivate our staff and we need to provide raises and other opportunities. So we do need to make some money in order to continue to grow the operation. Fully functional service organizations are extremely expensive and there is virtually no return on investment. We continue to evaluate our options and look for ways to reduce costs. This is transferred to the customer as indicated by the cost of maintenance contracts over the last five years increasing no more than $2 \%$ a year.

\section{Discussion with OEM representatives}

Q: One comment is that, coming from a University, we are in a poor position to keep paying these large service contracts. We are wondering which direction the philosophy is going. Are you trying to make it as opaque a possible so that we do have to have a service contract or are you trying to make it so that it is easy for the customer to quickly diagnose what the problem is and possibly even fix it themselves.

P. McGinley: If you look at the instruments from 10 years ago to today, you can see that the instruments are simpler for the user. There is much less service required on today's instruments than some of the older instruments. However, the complexity is growing with a great deal of electronics inside the instruments. I am sure most customers don't want to work with a lot of software. So we have to build into the software some diagnostic capability as well and we are doing that. The philosophy is developing where the computer systems on board are going to help you track down what part of the instrument is failing. As far as asking you to go inside the instrument and remove a board and swap it, there are going to be some customers who can do that but I don't think that is going to be the majority. The majority of customers are going to call us up and say, "My screen is telling me that I have a problem with my dif amp and you need to send somebody out with one."

Q: I sense a little bit of a dichotomy sometimes when I talk to service people. As OEMs, on one hand, you make a very good case for a necessary evil. But on the other hand, we seem to try to get away from service contracts. There is a tremendous resistance to losing service contract customers so sometimes, when the question of profit is brought up, the response is usually on the order of "our goal is to provide good customer satisfaction, keep the instruments running, and occasionally make a profit." It's okay for you to make a profit. We understand that sort of thing. But is it a necessary evil or is it a significant source of profit? I get a sense of both sometimes.

G. Rigby: I am exposing everything within our operation because basically we have nothing to hide. $8.3 \%$ of our revenue comes from spare parts, $10.5 \%$ from billable service, $67 \%$ comes from contract sales and $15.2 \%$ comes from new sales of instruments. Cost for parts is $7.8 \%$ and personnel is $53.4 \%$, which is a fixed cost. Travel and business related expenses are $36.4 \%$ and we are running a profit of $2.4 \%$. Contract revenue does generate a stable cash flow for us. Now we can't always control when a machine is going to break down. We can't always control the costs. For example, we have an E-beam lithography unit at a West Coast university and they have done their self-maintenance for years. The performance of that machine has deteriorated and they recently came back to us and requested that we get the machine back in shape. We spent a month and a half working on that machine with three engineers. It is a very sophisticated machine and this cost a significant amount of money. Did they save anything in the long-run? They probably saved a little bit of money but what did they lose in the performance of the tool by not being able to pattern what they were trying to pattern. We don't like to lose contracts because they are important for a stable cash flow. We don't like to lose the contracts, as they are a significant part of our income. If we don't have that revenue on a continuous basis with our head count the way it is, we would see huge fluctuations if we borrow from the bank to make the salary. Then we would get a big cash influx as billable revenue. It would make running the whole operation much more difficult. We have only a few thousand machines in the field. From this base we need to be able to properly run our business.

Pat McGinley: What that truly translates to is staffing. It would take us years to recover if we reduce our staffing to compensate for cost being too high relative to revenue. A trained engineer in this field is not someone we can go out to the schools and hire. We cannot expect to be able to train them and put them out in the field in a few months and they are able to operate. Our biggest scare, and the thing that worries us the most, is retaining the staff over time. We want to retain the $10-15$ years of experience that we have invested in these people. That really is the bottom line...stability for staffing.

Editor's Note: Because of space constraints, this valuable article was condensed by nearly a factor of two from the original. Many significant panalist comments and Q's \& A's were removed. If you would like a PDF of the original article, please make your request at microtoday@attglobal.net
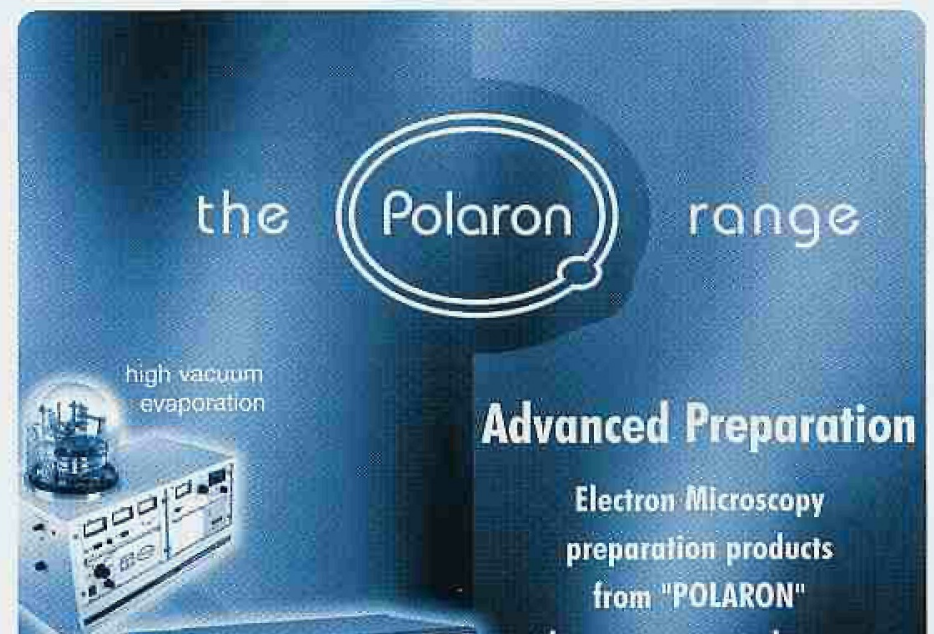
from "POLARON" the most respected name

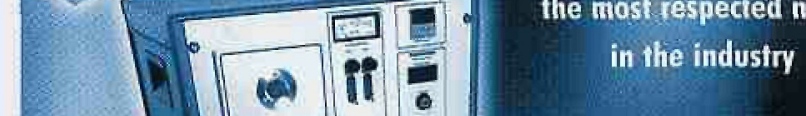
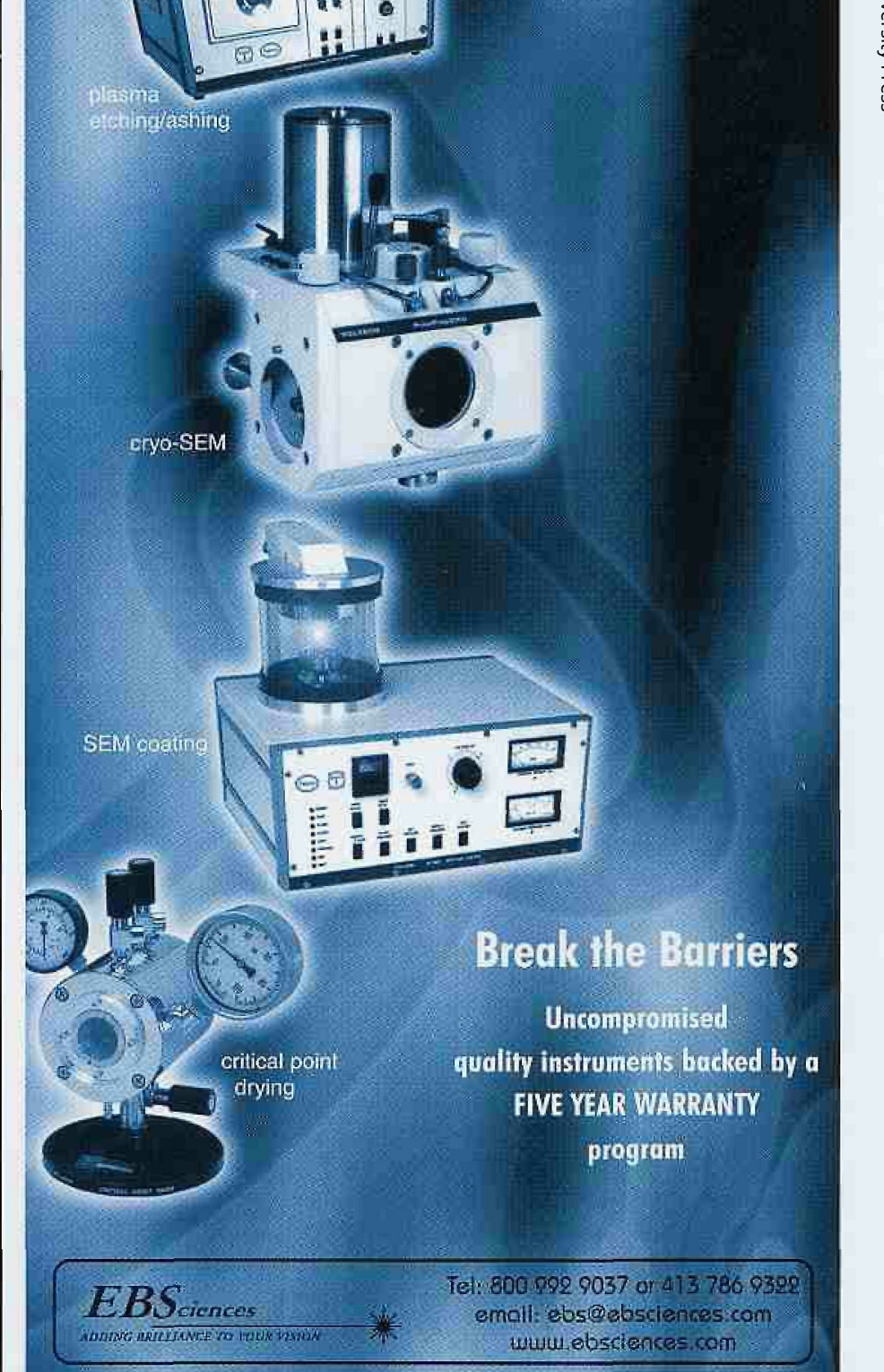

Contact us for critical point dryers, sputter coaters, curbon evaporators, high vacuum evaporators, plosmo reactors and many more..

\section{Whatglorumtech.com}

